\title{
Mid-sagittal Dimensions of Cervical Vertebral Bodies
}

\author{
PAUL R. KATZ, ${ }^{1}$ HERBERT M. REYNOLDS, ${ }^{1}$ DAVID R. FOUST ${ }^{1}$ \\ AND JANET K. BAUM ${ }^{2}$ \\ 1 Highway Safety Research Institute, University of Michigan, Ann Arbor, \\ Michigan 48105, and 2 Department of Radiology, Chelsea \\ Community Hospital, Chelsea, Michigan 48118
}

KEY WORDS Radiograph · Cervical spine · Vertebral body Ponderal index $\cdot$ Head weight.

\begin{abstract}
A series of lateral radiographs of the cervical spinal column was evaluated in order to determine vertebral body dimensions. The sample included males $(\mathrm{N}=30)$ and females $(\mathrm{N}=31) 18$ to 24 years old, comprising three stature percentile ranges $(1-20 ; 40-60 ; 80-99)$ of the U. S. adult popula tion. A two-dimensional analysis of vertebral body height (average distance between superior-inferior surfaces), depth (average distance between anteriorposterior surfaces), and area (average height $\times$ average depth) revealed minimal effects due to stature. In all subjects, average depth exceeded average height for vertebral bodies $\mathrm{C} 3$ through $\mathrm{C} 7$. Upon combining stature groups, both sexes revealed maximum average values for these dimensions at the seventh cervical vertebral body. Minimum average height occurred at C5 whereas minimum average depth was found at C3. Significant correlation $(\alpha<0.05)$ was found for males between ponderal index and height and depth of the $\mathrm{C} 7$ vertebra. Male head weight correlated significantly with C3, C4, $\mathrm{C} 5$ and $\mathrm{C} 6$ vertebral body height and with C3, C5 and C6 vertebral body depth. For females, C7 height and C6 depth correlated significantly with ponderal index and head weight respectively. Probable biomechanical relationships of specific cervical vertebral bodies are noted.
\end{abstract}

Increased research emphasis on the cervical spinal column may be attributed to the increase in neck injuries of "whiplash" type (Van Eck et al., '73). Although the anthropometrical and anatomical literature refers to vertebral body growth under normal and abnormal stress (Gooding and Newhauser, '65), to weights of particular components of the human vertebral column (Lawrance and Latiner, '67), and to total areas of the cord in various primates (Schon and Straus, '69), little information is available concerning actual dimensions of vertebral bodies of the cervical spine. Information providing cervical vertebral body size in the mid-sagittal plane became available as a result of the "Bio-engineering Study of Basic Physical Measurements related to Susceptibility to Cervical Hyperextension-Hyperflexion Injury," conducted at the Highway Safety Research Institute, University of Michigan (Snyder, Robbins and Chaffin, '72; Foust et al., '73). ${ }^{3}$ The study used human volunteer subjects of both sexes, 18 to 74 years old, selected as representative of the U.S. adult population according to the Department of HEW, National Center for Health Statistics (Stoudt et al., '65). All subjects were treated in accordance with the guidelines of the Institutional Guide to DHEW Policy on Protection of Human Subjects.

\section{MATERIALS AND METHODS}

A major portion of the cervical neck study involved a two-dimensional analysis of lateral radiographs of the cervical portion of the spinal column to determine ". . . measurements such as vertebral interspaces, bone to skin surface dimensions and neck angles ...." (Snyder et al., '72: p. 38). Three right lateral views were taken for each subject (fig. 1): (1) a neutral sitting position, (2) maximum voluntary flexion,

\footnotetext{
3 The research reported was sponsored by the Insurance Institute for Highway Safety, Washington, D.C
} 


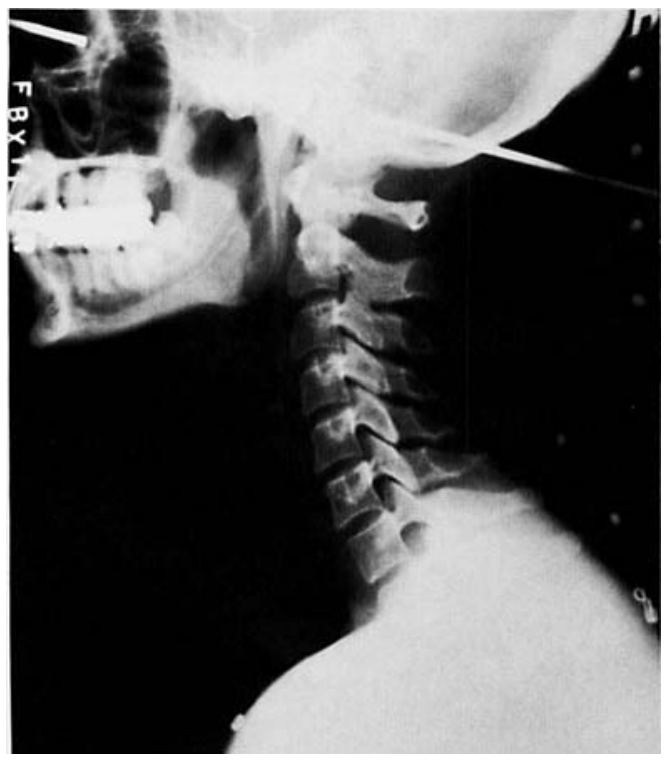

Fig. 1 Lateral radiograph of subject in neutral position. Rod oriented through nasion and tragion defines head position in relation to the vertical marker.

and (3) maximum voluntary extension. The subject was X-rayed in these positions while maintaining a relaxed seated posture in an unpadded chair with a seat back angle of $13^{\circ}$ from vertical and a seat pan angle of $6^{\circ}$ from horizontal (Snyder et al., '72). Radiographs were taken utilizing a Picker KM 200 Centurian II X-ray generator. The exposures were taken on $10 \times 12$ inch film with a tube-to-film distance of 60 inches. A small pendulum, marked in inches with lead shot, was positioned in the midsagittal plane and exposed in each film to provide a correction factor for magnification. The neutral-position films for 61 young subjects were analyzed to provide the data reported herein. Errors due to subject orientation and parallax are assumed to be constant. For each radiograph the cervical vertebral bodies were each marked (fig. 2) in the mid-sagittal plane according to the following definitions (Meschan, '68).

1. Most superior-anterior point.

2. Most superior-posterior point.

3. Most inferior-anterior point.

4. Most inferior-posterior point.

For each vertebra, the dimension of height (inferior-superior direction) was cal- culated by averaging the values of the segments defined as the distance between points $(1,3)$ and $(2,4)$. Similarly, depth (anterior-posterior direction) was defined as an average of the line segments $(1,2)$ and $(3,4)$. (Although true linearity does not exist for each vertebral body as described, similarities in shape between C3 through $\mathrm{C} 7$ minimize errors based upon the above approach.) Area was defined as the product of height and depth. All dimensions were obtained directly from the films using a Vernier caliper to the nearest tenth of a millimeter. Atlas and axis vertebrae were not included in this study because of their specialized shape and function.

Subject selection for the primary neck study was based upon sex, age, and stature and was designed to obtain a representative sampling of the United States adult population. Subject participation was based on approval of a previously-submitted health questionnaire. However, due to age-associated changes (e.g. arthritis) commonly detected in many older subjects, and the consequent introduction of error due to abnormal vertebral body shape, only the young age group (18-24 years) was analyzed for this study. No effort was made to achieve a racial balance (of the subjects reported herein, one was Black American, two were Oriental American and the remainder were White). Age being constant, the two primary variables analyzed were sex and stature (Snyder et al., '72). The resultant $2 \times 3$ matrix of data cells is shown in table 1.

A minimum of ten subjects, selected at random, were analyzed in each category. Occasionally, however, the seventh cervical vertebra could not be properly outlined thus resulting in a sample size of nine as reported in a few of the data cells in tables 2-7.

\section{RESULTS}

Dimensions of vertebral body height, depth and area were derived for each vertebra as described in the MATERIALS AND METHODs section and are reported in tabular form below. Average values and $95 \%$ confidence limits for each data cell are presented in graphic form in figure 3 . The following observations relate to these data. 
Height (Tables 2, 3)

1. Males have greater vertebral body heights, C3 through C7 (as seen in all stature groups), when compared to the corresponding female dimensions. 2. For all subjects, there is a progressive decrease in average vertebral body height from $\mathrm{C} 3$ through $\mathrm{C} 5$, and a progressive increase in height from $\mathrm{C} 5$ to $\mathrm{C} 7$ with the exception of C6 in the male 40-60\% ile stature group. Minimum average height for both sexes is found at C5. In all cases the seventh cervical vertebral body has the largest average height. 3 . Neither males nor females reveal a consistent trend for height between stature percentiles. However, both sexes do attain maximum average values for height, in all vertebrae, in the $80-99 \%$ ile (except females' C3).

Depth (Tables 4, 5)

1. The average depth for each male cervical vertebral body exceeds similar female dimensions from corresponding stature percentiles. 2. For all subjects, minimum values for vertebral body depth occur at C3. A progressive increase is noted for males with maximum depth attained at $\mathrm{C} 7$. Females in the $1-20 \%$ ile reveal a similar trend whereas maximum depth values occur at levels C6 and C7 in the two remaining female stature groups. 3 . The depth of male vertebral bodies increases with body stature, with maximum average values reached in the $80-90 \%$ ile for each vertebra. Females do not reveal similar stature differences.

For both males and females, the average depth is greater than the average height in all cases.

\section{Area (Tables 6, 7)}

1. Males have larger average vertebral body areas (noted for all stature groups) when compared to the corresponding values for females. 2. For males only, there is a consistent but slight decrease in area from C3 to C5. Females do not exhibit any apparent trends in these vertebrae. In both sexes, there is a progressive increase in area from $\mathrm{C} 5$ to $\mathrm{C} 7$, with maximum average values attained at $C 7.3$. In both male and female populations there is a progressive increase in average vertebral body area, from a minimum in the $1-20 \%$ ile
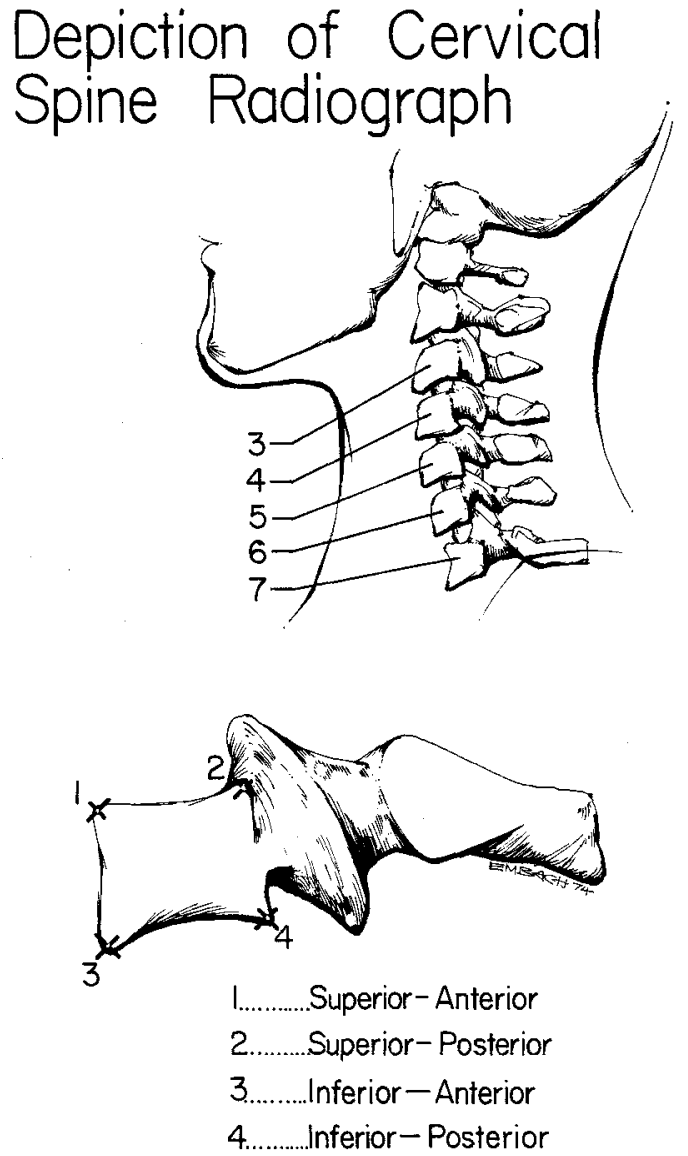

Fig. 2 Method of marking vertebral body for determining the dimensions of height and depth.

TABLE 1

Subject stature categories

\begin{tabular}{cccc}
\hline Subject & $\begin{array}{c}\text { Age } \\
(\mathrm{yr})\end{array}$ & $\begin{array}{c}\text { Stature } \\
(\mathrm{cm})\end{array}$ & $\begin{array}{c}\text { \% ile of } \\
\text { population } 1\end{array}$ \\
\hline Male & $18-24$ & $159-169$ & $1-20$ \\
& & $172.5-169$ & $40-60$ \\
& & $180-190$ & $80-99$ \\
Female & $18-24$ & $148.2-156.5$ & $1-20$ \\
& & $160-164$ & $40-60$ \\
& & $167.5-176$ & $80-99$
\end{tabular}

1 Based upon U. S. Dept. of Health, Education and Welfare "Weight, Height and Selected Body Dimensions of Adults," U. S. 1960-62. National Center for Health Statistics No. 1000, Series 11, No. 8. Table 2, p. 27.

to a maximum in the $80-90 \%$ ile. Of both sexes, one exception is that of $\mathrm{C6}$ in which the minimum area is found in the 40 $60 \%$ ile. 
TABLE 2

Height of male cervical ve rtebral bodies $(\mathrm{cm})$

\begin{tabular}{|c|c|c|c|c|c|c|c|c|c|c|c|c|}
\hline \multirow{2}{*}{$\begin{array}{l}\text { Ver- } \\
\text { tebral } \\
\text { body }\end{array}$} & \multicolumn{4}{|c|}{$1-20 \%$ ile } & \multicolumn{4}{|c|}{$40-60 \%$ ile } & \multicolumn{4}{|c|}{$80-99 \%$ ile } \\
\hline & $\mathbf{N}$ & $\overline{\mathrm{X}}$ & S.D. & C. V.1 & $\mathbf{N}$ & $\overline{\mathrm{X}}$ & S.D. & C. V. & $\mathbf{N}$ & $\overline{\mathrm{X}}$ & S.D. & C.V. \\
\hline C3 & 10 & 1.24 & 0.05 & 4.4 & 10 & 1.26 & 0.08 & 6.6 & 10 & 1.37 & 0.08 & 6.0 \\
\hline $\mathrm{C} 4$ & 10 & 1.18 & 0.11 & 9.1 & 10 & 1.22 & 0.07 & 6.0 & 10 & 1.34 & 0.07 & 5.2 \\
\hline C5 & 10 & 1.15 & 0.10 & 9.1 & 10 & 1.14 & 0.09 & 7.9 & 10 & 1.28 & 0.11 & 8.5 \\
\hline C6 & 10 & 1.18 & 0.12 & 10.2 & 10 & 1.13 & 0.09 & 7.7 & 10 & 1.29 & 0.09 & 6.6 \\
\hline C7 & 10 & 1.33 & 0.10 & 7.8 & 9 & 1.34 & 0.07 & 5.1 & 9 & 1.44 & 0.11 & 7.6 \\
\hline
\end{tabular}

$1 \%$ C.V. $=\frac{\text { S.D. }}{\mathrm{X}} \times 100$.

TABLE 3

Height of female cervical vertebral bodies ( $\mathrm{cm}$ )

\begin{tabular}{|c|c|c|c|c|c|c|c|c|c|c|c|c|}
\hline \multirow{2}{*}{$\begin{array}{l}\text { Ver- } \\
\text { tebral } \\
\text { body }\end{array}$} & \multicolumn{4}{|c|}{$1-20 \%$ ile } & \multicolumn{4}{|c|}{$40-60 \%$ ile } & \multicolumn{4}{|c|}{$80-99$ c ile } \\
\hline & $\mathbf{N}$ & $\overline{\mathrm{x}}$ & S.D. & C.V. ${ }^{1}$ & $N$ & $\overline{\mathrm{x}}$ & S.D. & C.V. & $N$ & $\overline{\mathrm{x}}$ & S.D. & C.V. \\
\hline C3 & 11 & 1.11 & 0.09 & 7.7 & 10 & 1.14 & 0.09 & 7.5 & 10 & 1.12 & 0.11 & 10.1 \\
\hline $\mathrm{C} 4$ & 11 & 1.07 & 0.09 & 8.9 & 10 & 1.10 & 0.10 & 8.8 & 10 & 1.11 & 0.12 & 11.0 \\
\hline C5 & 11 & 1.06 & 0.08 & 7.5 & 10 & 1.07 & 0.07 & 6.9 & 10 & 1.10 & 0.11 & 10.5 \\
\hline C6 & 11 & 1.08 & 0.08 & 7.8 & 10 & 1.08 & 0.07 & 6.4 & 10 & 1.15 & 0.08 & 6.7 \\
\hline C7 & 11 & 1.17 & 0.10 & 8.7 & 10 & 1.25 & 0.09 & 6.8 & 10 & 1.29 & 0.07 & 5.8 \\
\hline
\end{tabular}

$1 \%$ C.V. $=\frac{\text { S.D. }}{\mathrm{X}} \times 100$

TABLE 4

Depth of male cervical vertebral bodies (cm)

\begin{tabular}{|c|c|c|c|c|c|c|c|c|c|c|c|c|}
\hline \multirow{2}{*}{$\begin{array}{l}\text { Ver- } \\
\text { tebral } \\
\text { body }\end{array}$} & \multicolumn{4}{|c|}{$1-20 \%$ ile } & \multicolumn{4}{|c|}{$40-60 \%$ ile } & \multicolumn{4}{|c|}{$80-99 \%$ ile } \\
\hline & $\mathrm{N}$ & $\overline{\mathrm{x}}$ & S.D. & C.V. ${ }^{1}$ & $\mathbf{N}$ & $\overline{\mathrm{x}}$ & S.D. & c.V. & $N$ & $\overline{\mathrm{x}}$ & S.D. & C.V. \\
\hline $\mathrm{C} 3$ & 10 & 1.33 & 0.07 & 5.0 & 10 & 1.42 & 0.12 & 8.3 & 10 & 1.47 & 0.15 & 10.4 \\
\hline $\mathrm{C} 4$ & 10 & 1.38 & 0.08 & 6.0 & 10 & 1.44 & 0.07 & 4.6 & 10 & 1.50 & 0.12 & 7.8 \\
\hline $\mathrm{C} 5$ & 10 & 1.41 & 0.11 & 8.0 & 10 & 1.45 & 0.04 & 3.1 & 10 & 1.54 & 0.09 & 5.5 \\
\hline C6 & 10 & 1.47 & 0.12 & 8.4 & 10 & 1.53 & 0.07 & 4.5 & 10 & 1.60 & 0.07 & 4.1 \\
\hline $\mathrm{C} 7$ & 10 & 1.48 & 0.11 & 7.5 & 9 & 1.55 & 0.08 & 5.2 & 9 & 1.61 & 0.09 & 5.7 \\
\hline
\end{tabular}

$1 \%$ C.V. $=\frac{\text { S.D. }}{\mathrm{X}} \times 100$

A series of statistical tests was performed on the observations noted above. A two-way analysis of variance was performed for height, depth, and area for each vertebra to compare the effects of stature and sex. Analysis of variance tables were constructed for each test, and the appropriate $F$ statistics calculated. No statistically significant differences were noted for stature. However, statistically significant differences for sex at the 0.05 significance level were observed for vertebrae C3 (depth; area), C4 (depth), C6 (depth; area) and C7 (height; depth; area). Since analysis of variance indicated no stature effects but possible sex differences, the three stature groups were combined for each vertebra and a "t" test was performed. Exceptions to many of the trends outlined previously disappear upon combining stature groups within each sex category. The " $\mathrm{t}$ " statistics reveal that, in every case, males are significantly larger than females $(\alpha<0.05)$. This result is not surprising, since stature groups were selected as percentiles of the population rather than directly compared between sexes of similar statures. Future work might seek to compare vertebral body sizes for females and males of similar stature to test for significant differences in size based on sex. No such calculation was attempted in the present study.

The functional adaptation of bone to tensile and/or compressive stresses has been 
TABLE 5

Depth of female cervical vertebral bodies ( $\mathrm{cm}$ )

\begin{tabular}{|c|c|c|c|c|c|c|c|c|c|c|c|c|}
\hline \multirow{2}{*}{$\begin{array}{l}\text { Ver- } \\
\text { tebral } \\
\text { body }\end{array}$} & \multicolumn{4}{|c|}{$1-20 \%$ ile } & \multicolumn{4}{|c|}{$40-60 \%$ ile } & \multicolumn{4}{|c|}{$80-99 \%$ ile } \\
\hline & $\mathbf{N}$ & $\overline{\mathrm{X}}$ & S.D. & C.V.1 & $\mathbf{N}$ & $\tilde{\mathrm{x}}$ & S.D. & C.V. & $\mathbf{N}$ & $\overline{\mathrm{X}}$ & S.D. & C.V. \\
\hline C3 & 11 & 1.22 & 0.13 & 10.62 & 10 & 1.20 & 0.11 & 8.8 & 10 & 1.24 & 0.10 & 8.0 \\
\hline $\mathrm{C4}$ & 11 & 1.28 & 0.15 & 11.65 & 10 & 1.25 & 0.08 & 6.1 & 10 & 1.26 & 0.11 & 9.1 \\
\hline $\mathrm{C} 5$ & 11 & 1.31 & 0.13 & 10.34 & 10 & 1.31 & 0.11 & 8.2 & 10 & 1.30 & 0.12 & 9.2 \\
\hline $\mathrm{C} 6$ & 11 & 1.35 & 0.15 & 11.22 & 10 & 1.37 & 0.14 & 10.0 & 10 & 1.40 & 0.11 & 8.3 \\
\hline $\mathrm{C} 7$ & 11 & 1.37 & 0.14 & 10.10 & 10 & 1.37 & 0.11 & 7.8 & 10 & 1.40 & 0.09 & 6.4 \\
\hline
\end{tabular}

$1 \%$ C.V. $=\frac{\text { S.D. }}{\mathrm{X}} \times 100$

TABLE 6

Area of male cervical vertebral bodies ( $\mathrm{cm}$ )

\begin{tabular}{|c|c|c|c|c|c|c|c|c|c|c|c|c|}
\hline \multirow{2}{*}{$\begin{array}{l}\text { Ver- } \\
\text { tebral } \\
\text { body }\end{array}$} & \multicolumn{4}{|c|}{$1-20 \%$ ile } & \multicolumn{4}{|c|}{$40-60 \%$ ile } & \multicolumn{4}{|c|}{$80-99 \%$ ile } \\
\hline & $\mathbf{N}$ & $\overline{\mathrm{x}}$ & S.D. & C.V.1 & $\mathbf{N}$ & $\overline{\mathrm{x}}$ & S.D. & c.v. & $\mathbf{N}$ & $\overline{\mathrm{X}}$ & S.D. & C.v. \\
\hline $\mathrm{C} 3$ & 10 & 1.65 & 0.13 & 7.6 & 10 & 1.78 & 0.15 & 8.7 & 10 & 2.01 & 0.22 & 10.8 \\
\hline $\mathrm{C4}$ & 10 & 1.63 & 0.16 & 9.8 & 10 & 1.76 & 0.10 & 5.5 & 10 & 2.01 & 0.20 & 9.8 \\
\hline C5 & 10 & 1.62 & 0.20 & 12.4 & 10 & 1.66 & 0.14 & 8.5 & 10 & 1.97 & 0.20 & 10.4 \\
\hline C6 & 10 & 1.74 & 0.20 & 11.3 & 10 & 1.71 & 0.15 & 8.6 & 10 & 2.07 & 0.20 & 9.6 \\
\hline C7 & 10 & 1.96 & 0.21 & 10.9 & 9 & 2.08 & 0.18 & 8.8 & 9 & 2.33 & 0.23 & 9.9 \\
\hline
\end{tabular}

$1 \%$ C.V. $=\frac{\text { S.D. }}{\mathrm{X}} \times 100$.

TABLE 7

Area of female cervical vertebral bodies (cm)

\begin{tabular}{|c|c|c|c|c|c|c|c|c|c|c|c|c|}
\hline \multirow{2}{*}{$\begin{array}{l}\text { Ver- } \\
\text { tebral } \\
\text { body }\end{array}$} & \multicolumn{4}{|c|}{$1-20 \%$ ile } & \multicolumn{4}{|c|}{$40-60 \%$ ile } & \multicolumn{4}{|c|}{$80-99 \%$ ile } \\
\hline & $\mathbf{N}$ & $\overline{\mathrm{X}}$ & S.D. & C.V. 1 & $\mathbf{N}$ & $\bar{x}$ & S.D. & C.V. & $\mathbf{N}$ & $\overline{\mathrm{x}}$ & S.D. & C.V. \\
\hline C3 & 11 & 1.36 & 0.19 & 13.6 & 10 & 1.38 & 0.20 & 14.6 & 10 & 1.40 & 0.23 & 16.1 \\
\hline $\mathrm{C} 4$ & 11 & 1.37 & 0.22 & 15.8 & 10 & 1.38 & 0.19 & 13.9 & 10 & 1.41 & 0.26 & 18.6 \\
\hline C5 & 11 & 1.36 & 0.19 & 13.9 & 10 & 1.40 & 0.19 & 13.0 & 10 & 1.45 & 0.27 & 18.6 \\
\hline C6 & 11 & 1.47 & 0.25 & 16.6 & 10 & 1.44 & 0.14 & 9.6 & 10 & 1.61 & 0.23 & 14.3 \\
\hline $\mathrm{C} 7$ & 11 & 1.62 & 0.26 & 15.9 & 10 & 1.68 & 0.22 & 12.9 & 10 & 1.81 & 0.21 & 11.4 \\
\hline
\end{tabular}

$1 \%$ C.V. $=\frac{\text { S.D. }}{\mathrm{X}} \times 100$.

employed as a useful hypothesis in the study of bone growth and development (Evans, '57). The intent, therefore, was to relate dimensions of the cervical vertebral bodies to stresses of probable consequence. The subsequent comparison employed measures of head weight and body build as indicators of forces acting upon the spinal column. Head weight was calculated from the following regression equation derived by Clauser et al. ('69: p. 46);

$$
\begin{aligned}
\text { Head weight } & =0.104 \text { (head circumference) } \\
& +0.015 \text { (body weight })-2.189 .
\end{aligned}
$$

A measure of body build was taken as the ponderal index (height $/{ }^{3} \mathrm{~V}$ weight). Although a less accurate measure of build in the ... "later decades of life ..." (Sheldon et al., '40: pp. 265-266), the ponderal index remains a reliable guide in the younger age groups (18-24 years) pertinent to this study (Heath, '63).

Results obtained from correlating head weight and ponderal index with height and depth of vertebral bodies C3 through $\mathrm{C} 7$ are presented in table 8 . (The variation in vertebral body size explained by head weight and ponderal index is equivalent to $\mathrm{r}^{2}$.) Correlation coefficients significant at $\alpha<0.05$ were found for the following:

1. Male ponderal index: C7 height and depth;

2. Male head weight: C3, C5 and C6 height and depth, and $\mathrm{C} 4$ height; 


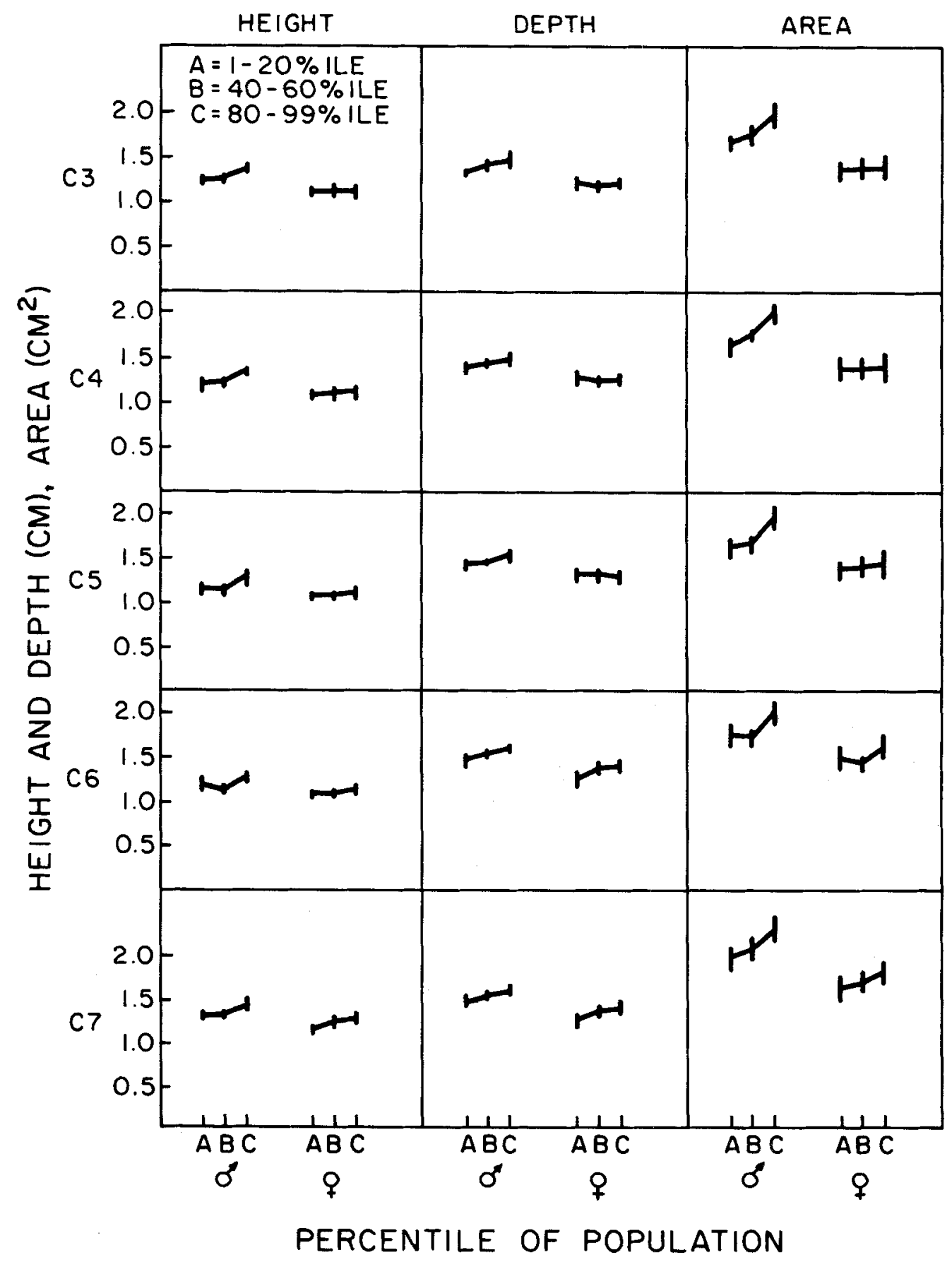

Fig. 3 Average vertebral body dimensions and $95 \%$ confidence intervals according to sex and stature. 
TABLE 8

Correlation coefficients for indices of stress with vertebral body height and depth

\begin{tabular}{lcccc}
\hline & \multicolumn{2}{c}{ Male } & & Female \\
\cline { 2 - 5 } & H.W. & P.I & H.W. & P.I. \\
\hline C3 Height & 0.47401 & 0.2221 & 0.2629 & 0.1791 \\
C4 Height & 0.40341 & 0.2911 & 0.2150 & 0.2596 \\
C5 Height & 0.45701 & 0.1554 & -0.0542 & 0.3137 \\
C6 Height & 0.43651 & 0.0543 & 0.0219 & 0.3644 \\
C7 Height & -0.2728 & 0.45281 & 0.2568 & 0.50631 \\
C3 Depth & 0.40741 & -0.0112 & 0.2625 & 0.1533 \\
C4 Depth & -0.3309 & 0.1074 & 0.1619 & 0.0931 \\
C5 Depth & 0.39281 & 0.0634 & 0.2988 & 0.1190 \\
C6 Depth & 0.40121 & 0.1484 & 0.39501 & 0.2741 \\
C7 Depth & -0.3308 & 0.44061 & 0.3522 & 0.2396 \\
\hline
\end{tabular}

P.I., Ponderal index.

H. W., Head weight.

$1(\alpha=0.05)$.

3. Female ponderal index: $\mathrm{C} 7$ height;

4. Female head weight: C6 depth.

\section{CONCLUSION}

The study reported herein has provided previously unavailable dimensional information concerning the third through seventh cervical vertebrae. Two-dimensional mid-sagittal measurements of the human cervical spine, the effects of sex and stature on these measurements, and the presence of size trends within the spinal column are of value to researchers investigating various aspects of the spine. The data presented demonstrate that although there are no significant stature differences:

1. Average vertebral body depth exceeds that of height for both sexes.

2. Upon combining stature groups, the vertebral body of $\mathrm{C} 7$ was found to have the largest average height and depth for both males and females; the smallest average values are found in $\mathrm{C} 5$ for height and C3 for depth. Male vertebrl body area also attains minimum values at $\mathrm{C5}$. Data from Snyder, Chaffin and Shutz's ("72) study of cervical vertebral interspaces, in the determination of cervical spine mobility, reveal trends similar to those outlined above. As these authors have indicated, vertebrae C3 through C5 are most consistently affected by head inclination, unlike the vertebrae below (97: pp. 8188). The present study has yielded further evidence as to the "pivotal" nature of C5. The casual observation of increasing vertebral body size as one descends the spinal column must now be refined to include specific variations within particular segments of the spine.

3. Males exceed females, to a statistically significant degree, in the dimensions of height, depth and area for cervical vertebral bodies $\mathrm{C} 3$ through $\mathrm{C} 7$.

4. The seventh cervical vertebral body has the largest average mid-sagittal crosssectional area for both males and females.

5. Upon testing for possible relationships between stress indication and vertebral body size, ponderal index was found to correlate at the $5 \%$ significance level with the height and depth of the males' seventh cervical vertebral body, and with the height of the females' $\mathrm{C} 7$ body. Male head weight correlates significantly with C3 for depth. Male vertebral body area and with C3, C5 and C6 vertebral body depth. Female head weight correlates significantly with $\mathrm{C} 6$ vertebral body depth. In contrast to previously held assumptions, the seventh cervical vertebra's response to head weight appears minimal, whereas the effects of overall body build take on added significance. Further evaluation of both thoracic and cervical vertebrae may reveal that $\mathrm{C} 7$ is influenced more by forces known to affect the vertebrae directly beneath it rather than those above it.

\section{ACKNOWLEDGMENT}

The authors gratefully acknowledge John Ferguson for his assistance with the computerized data analysis and James Embach for the cervical spine illustration. 


\section{LITERATURE CITED}

Clauser, C., J. McConville and J. W. Young 1969 Weight, volume and center of mass of segments of the human body. Report AMRL-TR-69-70. Wright-Patterson Air Force Base, Ohio.

Evans, F. G. 1957 Stress and Strain in Bones Their Relation to Fractures and Osteogenesis. Charles C Thomas, Publisher, Springfield.

Foust, D. R., D. B. Chaffin, R. G. Snyder and J. K. Baum 1973 Cervical range of motion and dynamic response and strength of cervical muscles. In: Proceedings of the Seventeenth Stapp Car Crash Conference. SAE Report No 730795, New York, pp. 285-308.

Gooding, C. A., and E. Newhauser 1965 Growth and development of the vertebral body in the presence and absence of normal stress. Amer. Jour. of Roent., 93: 388-393.

Heath, B. H. 1963 Need for modification of somatotype methodology. Amer. Jour. Phys. Anthrop, 21: 227-233.

Lawrance, E. W., and H. B. Latiner 1967 Weights and variability of components of the human vertebral column. Anat. Rec., 159: 83 88.

Meschan, J. 1968 Radiographic Positioning and Related Anatomy. W. B. Saunders Co., Philadelphia.
Schon, M. A., and W. L. Straus 1969 On the proportions between some areas of th first cervical segment of the spinal cord of primates. Nat. Acad. Sci. Proc., 63: 1174-1180.

Sheldon, W. H., S. S. Stevens and W. B. Tucker 1940 The Varieties of Human Physique. Harper Brothers Publishers, New York.

Snyder, R. G., D. B. Chaffin and R. K. Schutz 1972 Link system of the human torso. Report AMRL-TR-71-88. Wright-Patterson Air Force Base, Ohio.

Snyder, R. G., D. H. Robbins and D. B. Chaffin 1972 Bioengineering study of basic physical measurements related to susceptibility to cervical hyperextension-hyperflexion. First Quarterly Report prepared for Insurance Institute for Highway Safety, Washing ton, D.C.

Stoudt, H. W., A. Damon and R. McFarland 1965 Weight, height and selected body dimensions of adults: United States, 1960-62. USPHS Publication No. 1000, Series 11, No. 8.

Van Eck, P., D. B. Chaffin, D. R. Foust, J. Baum and R. G. Snyder 1973 A bibliography of whiplash and cervical kinematic measurement. Highway Safety Research Institute, the University of Michigan. Publication prepared for Insur ance Institute for Highway Safety, Washington, D.C. 